\title{
Improved survival in patients with diabetic nephropathy
}

\author{
E. R. Mathiesen ${ }^{1,2}$, K. Borch-Johnsen ${ }^{1}$, D. V.Jensen ${ }^{1}$ and T. Deckert ${ }^{1}$ \\ ${ }^{1}$ Steno Memorial Hospital, Gentofte, and ${ }^{2}$ Hvidøre Hospital, Klampenborg, Denmark
}

Summary. The effect of early antihypertensive treatment on survival of patients with diabetic nephropathy was evaluated by studying two cohorts of Type 1 (insulin-dependent) diabetic patients developing persistent proteinuria in $\mathrm{I}$ : 1957-1973 (late treatment group $n=49$ ) and II: 1979-1983 (early treatment group $n=71$ ). At onset of nephropathy, the two cohorts were comparable with regard to age $(29(8)$ vs $30(8)$ years, mean (SD)), duration of diabetes $(16(6)$ vs $18(7)$ years), blood pressure $(132(16) / 85(11)$ vs $134(16) / 86(8) \mathrm{mm}$ $\mathrm{Hg}$ ), proteinuria $\left(0.8(0.5-1.2)\right.$ vs $0.8(0.6-1.2) \mathrm{g} \times 24 \mathrm{~h}^{-1}$, median (quartiles)) and serum creatinine $(87(14)$ vs $85(16)$ $\left.\mu \mathrm{mol} \times 1^{-1}\right)$. The patients were followed frequently at the outpatients' clinic until death or for a median duration of 8 years.
In the first cohort antihypertensive treatment was seldom used, whereas, in the second cohort antihypertensive treatment was started when blood pressure reached 144(18)/93(7) $\mathrm{mm} \mathrm{Hg}$. The probability of survival with a functioning kidney for more than 8 years was $48 \%$ in the first cohort and $87 \%$ in the second cohort, $p<0.001$. The improvement of survival was due mainly to a decreased mortality from uraemia. Early antihypertensive treatment is the most likely explanation for this improvement.

Key words: Diabetic nephropathy, Type 1 (insulin-dependent) diabetes mellitus, blood pressure, antihypertensive treatment, survival, renal failure.
Type 1 (insulin-dependent) diabetes is characterised by a high relative mortality, which is confined almost entirely to patients developing diabetic nephropathy [1] Diabetic nephropathy is characterised by persistent proteinuria, increase in blood pressure and an inevitable decline in glomerular filtration rate [2]. Uraemia is the main cause of death but cardiovascular diseases also contribute significantly to the excess mortality [1]. In small selected series of patients with Type I diabetes and nephropathy antihypertensive treatment has been shown to reduce the rate of decline in kidney function $[3,4]$ but the impact on survival has not been elucidated.

The aim of the present study was to investigate the impact of early antihypertensive treatment on the overall survival in patients with diabetic nephropathy followed under routine conditions in the outpatients' clinic.

\section{Subjects and methods}

All Type 1 diabetic patients with age at diagnosis $<31$ years admitted to the Steno Memorial Hospital before 1983 were identified [1]. These patients were screened for protein excretion routinely at each visit and while hospitalized [1]. If proteinuria was detected, quantitative determination was carried out by the Esbach method [5].
From this population we identified all regular attenders with a well defined date of onset of persistent proteinuria (protein excretion exceeding $0.5 \mathrm{~g} / 24 \mathrm{~h}$ in three consecutive urine samples) in the periods 1959-1973 and 1979-1983. Onset of diabetic nephropathy was defined as the first of these elevated urinary protein excretions. Serum creatinine had to be within normal limits with no other known kidney or urinary tract disease. All patients with onset of diabetic nephropathy within the first 40 years of diabetes were included in the study.

The patients were seen regularly at the Steno Memorial Hospital every 4 months. Protein excretion and blood pressure were measured and possible antihypertensive treatment was adjusted at every visit. Serum creatinine [6], $\mathrm{HbA}_{1 \mathrm{c}}$ (after 1979, normal range 4.1-6.4), weight, urinary microscopy and ophthalmoscopy were registered annually. The patients were followed to death or for at least 5 and if possible up to 8 years. The cause of death was obtained from the death certificates and confirmed by the files of the hospital where the patients died.

In the first cohort (1959-1973) antihypertensive treatment was seldom used and only when diastolic blood pressure exceeded $110 \mathrm{~mm} \mathrm{Hg}$ or treatment with diuretics was necessary because of severe oedema. In the second cohort (1979-1983) antihypertensive treatment was instituted as routine treatment when diastolic blood pressure exceeded $95 \mathrm{~mm} \mathrm{Hg}$ on three consecutive occasions or if the patient had fluid retention. According to our plan for routine antihypertensive treatment, diuretics (thiazide or frusemide) were the first drugs of choice. When a combination of two or more drugs was necessary a cardioselective betablocker was preferred but also hydralazine, ACE- inhibitors and calcium blockers were used. The protein content in the prescribed diet was $20 \%$ of the total kilojoules intake and did not change during the observation period. 


\section{Statistical analysis}

The two cohorts were compared with unpaired Student $t$-test or Mann-Whitneys test (protein excretion). The data are expressed as mean (SD) or median (quartiles). The survival analysis of the two groups was compared by Kaplan-Meier estimates using log rank test. In the survival analysis patients undergoing dialysis or kidney transplantation were counted as non-survivors. $p<0.05$ was considered as significant.

\section{Results}

At onset of diabetic nephropathy the clinical condition of the two cohorts was comparable and mean blood pressure was approximately $133 / 85 \mathrm{~mm} \mathrm{Hg}$ in both groups (Table 1). With increased duration of nephropathy the blood pressure rose in cohort I while it was kept constant in cohort II receiving early antihypertensive treatment (Fig. 1). From the second year of diabetic nephropathy there was a significant difference in both systolic and diastolic blood pressure between the two cohorts. Mean blood pressure at the start of antihypertensive treatment was $144(18) / 93(7) \mathrm{mm} \mathrm{Hg}$ in the second cohort.

The probability of survival with a functioning kidney for more than 8 years was $48 \%$ in the first cohort and $87 \%$ in the second cohort, $X^{2}=12.54, p<0.001$ (Fig.1). In the first cohort 18 patients died and one underwent kidney transplantation (total 39\%) within the first 8 years of diabetic nephropathy. Uraemia was the main cause of death (13 patients) and five died from myocardial infarction. In the second cohort five patients died and two underwent transplantation (total $10 \%$ ). The causes of death were: Uraemia (1), myocardial infarction (2), ketoacidosis (1) and suicide (1). Serum creatinine values in the nine patients dying from non-renal causes was 110 (range $82-200$ ) $\mu \mathrm{mol} \times 1^{-1}$.

Out of the 34 patients from the second cohort who had nephropathy diagnosed prior to 1981, 32 (14 women) patients were still alive 8 years later. Mean

Table 1. Clinical data at onset of nephropathy in Type 1 (insulin-dependent) diabetic patients offered early antihypertensive treatment (cohort II) compared to patients not offered early antihypertensive treatment (cohort I)

\begin{tabular}{lll}
\hline & Cohort I & Cohort II \\
\hline Onset of nephropathy & $1959-1973$ & $1979-1983$ \\
Number $(\mathrm{F} / \mathrm{M})$ & $49(14 / 35)$ & $71(32 / 39)$ \\
Age (years) & $29.1(8)$ & $30.2(8)$ \\
Duration of diabetes $($ years $)$ & $15.8(6)$ & $17.7(7)$ \\
Body mass index $\left(\mathrm{kg} \times \mathrm{m}^{-2}\right)$ & $22.4(3)$ & $22.8(2)$ \\
Blood pressure $(\mathrm{mm} \mathrm{Hg})$ & $132(16)$ & $134(16)$ \\
& $84.5(11)$ & $85.7(8)$ \\
Protein excretion $\left(\mathrm{g} \times 24 \mathrm{~h}^{-1}\right)$ & $0.8(0.5-1.1)$ & $0.8(0.6-1.2)$ \\
Serum creatinine $\left(\mu \mathrm{mol} \times 1^{-1}\right)$ & $87(14)$ & $85(16)$ \\
Proliferative retinopathy $(\%)$ & $22(11 / 49)$ & $25(18 / 71)$ \\
\hline
\end{tabular}

Mean (SD) or median (quartiles) are given
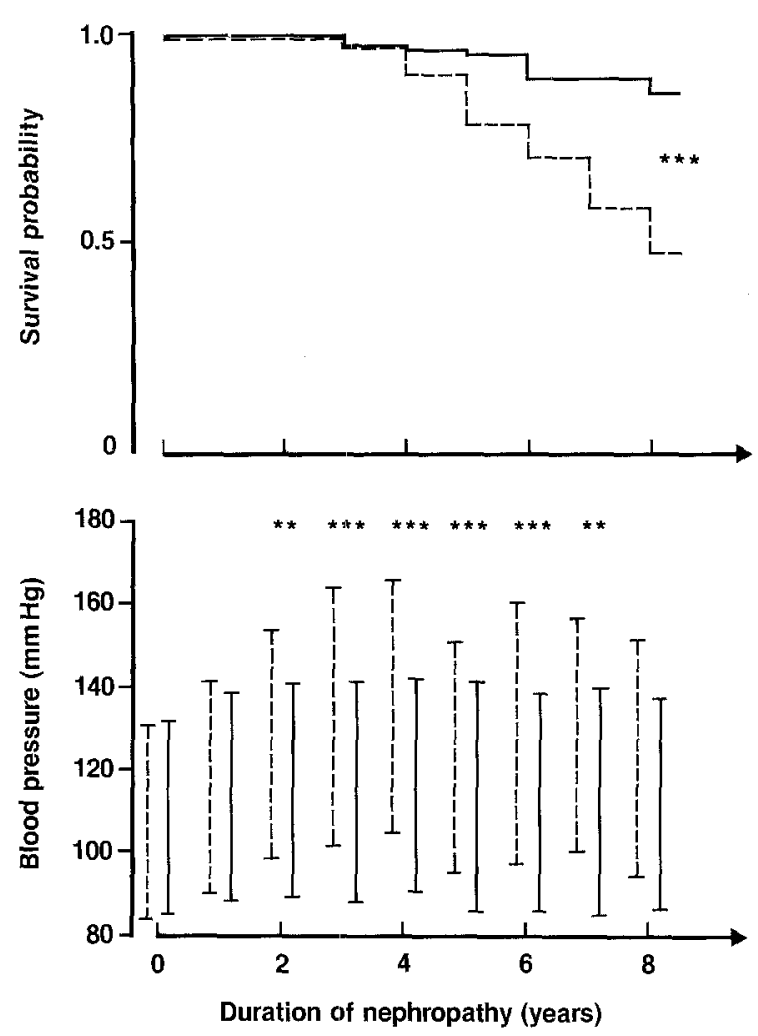

Fig. 1. Blood pressure and survival probability in relation to duration of nephropathy in Type 1 (insulin-dependent) diabetic patients with (cohort II -) and without (cohort I --) early antihypertensive treatment. ** $p<0.01, * * * p<0.001$

age and duration of diabetes were $37(8)$ and $26(8)$ years, respectively. All except four were receiving antihypertensive treatment with at least one drug. Blood pressure was $139(22) / 85(9) \mathrm{mm} \mathrm{Hg}$, the protein excretion 1.2 $(0.5-2.4) \mathrm{g} / 24 \mathrm{~h}$, and serum creatinine $110(92-134)$ $\mu \mathrm{mol} \times 1^{-1}$. None of these 32 patients were treated with dialysis or kidney replacement therapy. Seven patients had background retinopathy and 25 proliferative retinopathy. Three (9\%) were blind. Mean $\mathrm{HbA}_{1 \mathrm{c}}$ was $9.9 \%$ (2) and mean of all measured $\mathrm{HbA}_{1 \mathrm{c}}$ values was $9.5(2) \%$ during the 8 years of follow-up in the second cohort.

\section{Discussion}

Our cohort study has shown that the survival of patients with Type 1 diabetes and nephropathy has improved substantially since early antihypertensive treatment has become routine treatment in our clinic. The improved survival was mainly due to decreased mortality from uraemia.

With our present knowledge of the effect of antihypertensive treatment on preservation of kidney function in diabetic nephropathy, we found it unethical to initiate a study with a randomized design to investigate the effect on survival. This study was, therefore, conducted as a cohort study of early antihypertensive treatment with a historical control cohort from the pre-anti- 
hypertensive era. All the patients were followed at the same clinic with essentially the same method for determination of serum creatinine, blood pressure and quantitative measurement of protein in the urine during the whole study period. At onset of nephropathy the two groups were well matched with regard to all clinical parameters except the sex ratio. However, mortality in patients with nephropathy is independent of gender [1]. The median survival in the first cohort was 8 years which is in accordance with previous studies of patients with diabetic nephropathy $[1,7]$. The higher number of patients included in the second cohort is not due to a higher incidence of diabetic nephropathy, but due to a larger number of diabetic patients referred for regular control at the Steno Memorial Hospital. None of the patients dropped out during follow-up.

The calendar-period of the first cohort was selected as close to the second cohort as possible to minimize a potential calendar effect on mortality $[1,7]$. The protein content in the prescribed diabetic diet and the strategy of blood glucose control were unchanged during the observation period and salt restriction never recommended. A mean $\mathrm{HbA}_{1 \mathrm{c}}$ of $9.5 \%$ in the second cohort indicate that strict metabolic control is unlikely to be responsible for the improved survival. Moreover, the impact of strict metabolic control on the progression of established nephropathy is of minor importance $[8,9]$ compared to the effect of antihypertensive treatment $[3$, 4].

The mean blood pressure in the second cohort was up to $15 \mathrm{~mm} \mathrm{Hg}$ lower according to the difference in antihypertensive strategy. The observed decline in deaths due to uraemia in the second cohort is in accordance with the effect of antihypertensive treatment on the rate of decline in glomerular filtration rate in diabetic nephropathy $[3,4]$. Patients in dialysis or having kidney replacement therapy were counted as nonsurvivors to exclude an influence on the survival rate by changes in the treatment of end-stage renal failure. Despite the fact that myocardial infarction was the cause of death in 5 out of 49 vs 2 out of 71 patients, the numbers were too small to demonstrate any significant decline in cardiovascular mortality.

In conclusion, our study demonstrated a substantial improvement in survival with preserved kidney function in Type 1 diabetic patients with nephropathy. Antihypertensive treatment is the most likely explanation for this improvement.

\section{References}

1. Borch-Johnsen K, Andersen PK, Deckert T (1985) The effect of proteinuria on relative mortality in Type 1 (insulin-dependent) diabetes mellitus. Diabetologia 28: 590-596

2. Parving $\mathrm{H}-\mathrm{H}$, Smidt UM, Friisberg B, Bonnevie-Nielsen V, Andersen AR (1981) A prospective study of glomerular filtration rate and arterial blood pressure in insulin-dependent diabetics with diabetic nephropathy. Diabetologia 20: 457-461

3. Mogensen CE (1982) Long-term antihypertensive treatment inhibiting progression of diabetic nephropathy. $\mathrm{Br}$ Med J 285: 685-688

4. Parving $\mathrm{H}-\mathrm{H}$, Andersen A, Smidt U, Hommel E, Mathiesen E, Svendsen PAA (1987) Effect of antihypertensive treatment on kidney function in diabetic nephropathy. Br Med J 294: 1443-1447

5. Astrup P, Brøchner-Mortensen K, Faber M (1959) Clinical laboratory techniques. August Bang, Copenhagen

6. Richterich R (1965) Klinische Chemie. Karger, Basel New York, $\mathrm{pp} 212-213$

7. Krolevski AS, Warram JH, Christlieb AR, Busick EJ, Kahn CR (1985) The changing natural history of nephropathy in type 1 diabetes. Am J Med 78: 785-794

8. Viberti GC, Bilous RW, Mackintosh B, Bending JJ, Keen H (1983) Long-term correction of hyperglycaemi and progression of renal failure in insulin-dependent diabetes. Br Med J 286: 598-602

9. Nyberg G, Blohme G, Nordeen G (1987) Impact of metabolic control in progression of clinical diabetic nephropathy. Diabetologia 30: $82-86$

Received: 21 August 1989

Dr. E. R. Mathiesen

Steno Memorial Hospital

Niels Steensens vej 2

DK-2820 Gentofte

Denmark 